\title{
O BRINQUEDO DE MIRITI, MEMÓRIAS COLETIVAS E CONSUMO DURANTE O CÍRIO DE NAZARÉ EM BELÉM DO PARÁ
}

\author{
Shirley do Socorro Moura das NEVES \\ Edgar Monteiro CHAGAS JUNIOR
}

\begin{abstract}
RESUMO
O presente artigo pretende discutir a vertente do brinquedo de miriti enquanto símbolo de memória coletiva e que passa a partir disso a traduzir uma narrativa de cultura, esta amazônica. Seu principal ponto de discussão versa sobre a tensão dos avanços das demandas geradas pelo consumo durante o período da festa do Círio de Nazaré. Desta forma, pretende-se analisar a relação do brinquedo de miriti enquanto memória coletiva em contraponto com o consumo cultural durante a festa religiosa de Nossa Senhora de Nazaré em Belém de Pará. Propõe-se também discutir como o brinquedo de miriti compõe o cenário do consumo religioso, e sua relação com a tradição herdada de um povo. A metodologia utilizada foi a da pesquisa bibliográfica em diálogos com teóricos que elucidem conceitos acerca dos pontos de discussão que serão abordados em vias dos elos entre memória, tradição e identidade.
\end{abstract}

Palavras-chave: Brinquedo de miriti; Memória; Cultura; Consumo.

\section{THE MIRITI TOY, COLLECTIVE MEMORIES AND CONSUMPTION DURING THE CIRCLE OF NAZARÉ IN BELÉM DO PARÁ}

\begin{abstract}
The present article intends to discuss the toy strand of miriti as a symbol of collective memory and that goes from this to translate a narrative of culture, this amazonian. Its main point of discussion is about the tension of the advances of the demands generated by consumption during the period of the feast of the Cirio de Nazaré. In this way, we intend to analyze the relation of the toy of miriti as a collective memory in counterpoint with the cultural consumption during the religious feast of Our Lady of Nazaré in Belém de Pará. It is also proposed to discuss how the toy of miriti composes the scene of the religious consumption, and its relation to the tradition inherited from a people. The methodology used was the bibliographical research in dialogues with theorists that elucidate concepts about the points of discussion that will be approached along the links between memory, tradition and identity.
\end{abstract}

Keywords: Miriti toy; Memory; Culture; Consumption.

\section{EL JUGUETE MIRITI, RECUERDOS COLECTIVOS Y CONSUMO DURANTE EL CÍRCULO DE NAZARÉ EN BELÉM DO PARÁ}

\section{RESUMEN}

El presente artículo pretende discutir la línea de juguetes de miriti como un símbolo de la memoria colectiva y eso se traduce en una narrativa de la cultura, esta amazona. Su principal punto de discusión es sobre la tensión de los avances de las demandas generadas por el consumo durante el período de la fiesta del Círio de Nazaré. De esta manera, pretendemos analizar la relación del juguete de miriti como una memoria colectiva en contrapunto con el consumo cultural durante la fiesta religiosa de Nuestra Señora de Nazaré en Belém de Pará. También se propone discutir cómo el juguete de miriti compone la escena del El consumo religioso, y su relación con la tradición heredada de un pueblo. La metodología utilizada fue la investigación bibliográfica en diálogos con teóricos que aclaran conceptos sobre los puntos de discusión que se abordarán a lo largo de los vínculos entre memoria, tradición e identidad.

Palabras clave: Juguete de miriti; Memoria cultura; Consumo.

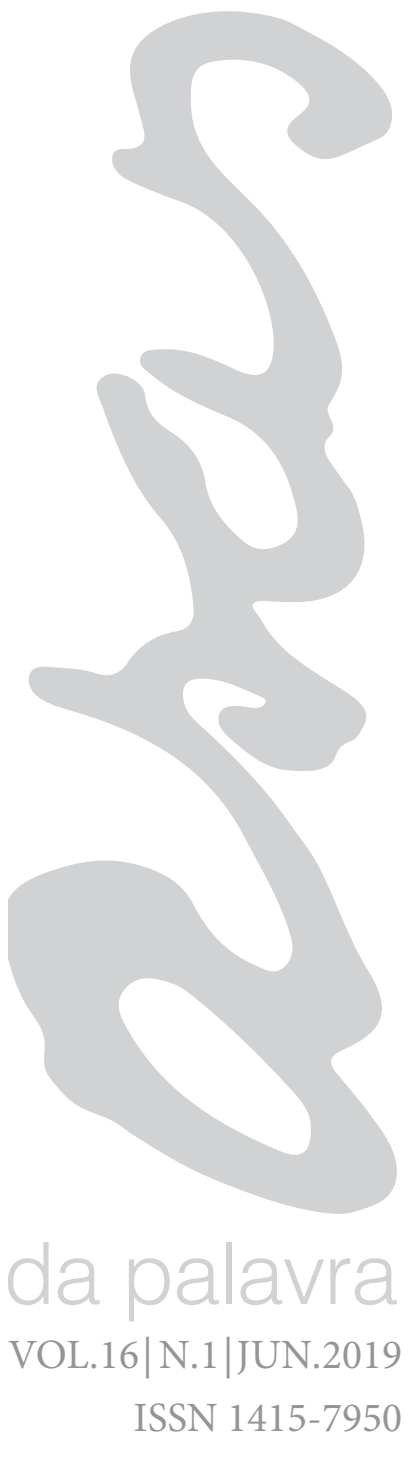




\section{INTRODUÇ̃̃O}

A festa do Círio de Nossa Senhora de Nazaré que ocorre na capital de Belém do Pará, é uma das maiores e mais belas festas católicas do Brasil, e atrai todos os anos milhares de fiéis de todos os lugares do mundo. É uma procissão no segundo domingo de outubro, mas que reuni ao longo de sua quadra nazarena em quinze dias de festa, um permeado de eventos e atividades que traduzem sentimentos, representações e manifestações culturais do povo paraense, que se costuma igualar aos festejos do período das festas natalinas.

A palavra "círio" vem do latim cereus, que significa vela (cera), segundo o autor Figueiredo $(2005$, p. 20). Para ele, essa devoção a Nossa Senhora de Nazaré é realizada há mais de 200 anos, desde 1793. "O círio é hoje o acontecimento fundador da sociedade paraense, [...] marcando sua identidade, conjugando culturas e éticas. É uma explosão dos sentidos e das paixões" (FIGUEIREDO, 2005, p. 21). Durante toda essa conjunção de valores, temos os brinquedos de miriti imersos nessa dinâmica social onde

1 Estrutura que tem a forma de uma cruz de braço duplo, feita com pedaços do mesmo material, tendo por volta de 2 metros na haste vertical e 1 metro nos braços horizontais. se apresentam majestosos em suas girândolas ${ }^{1}$, sendo capazes de representar toda a criatividade e maestria do artesão, que se apropria de acontecimentos coletivos, dos meios de comunicação e de sua herança cultural para confeccioná-los, sempre cheios de muitas cores e alegria, como podemos ver na figura 1 .

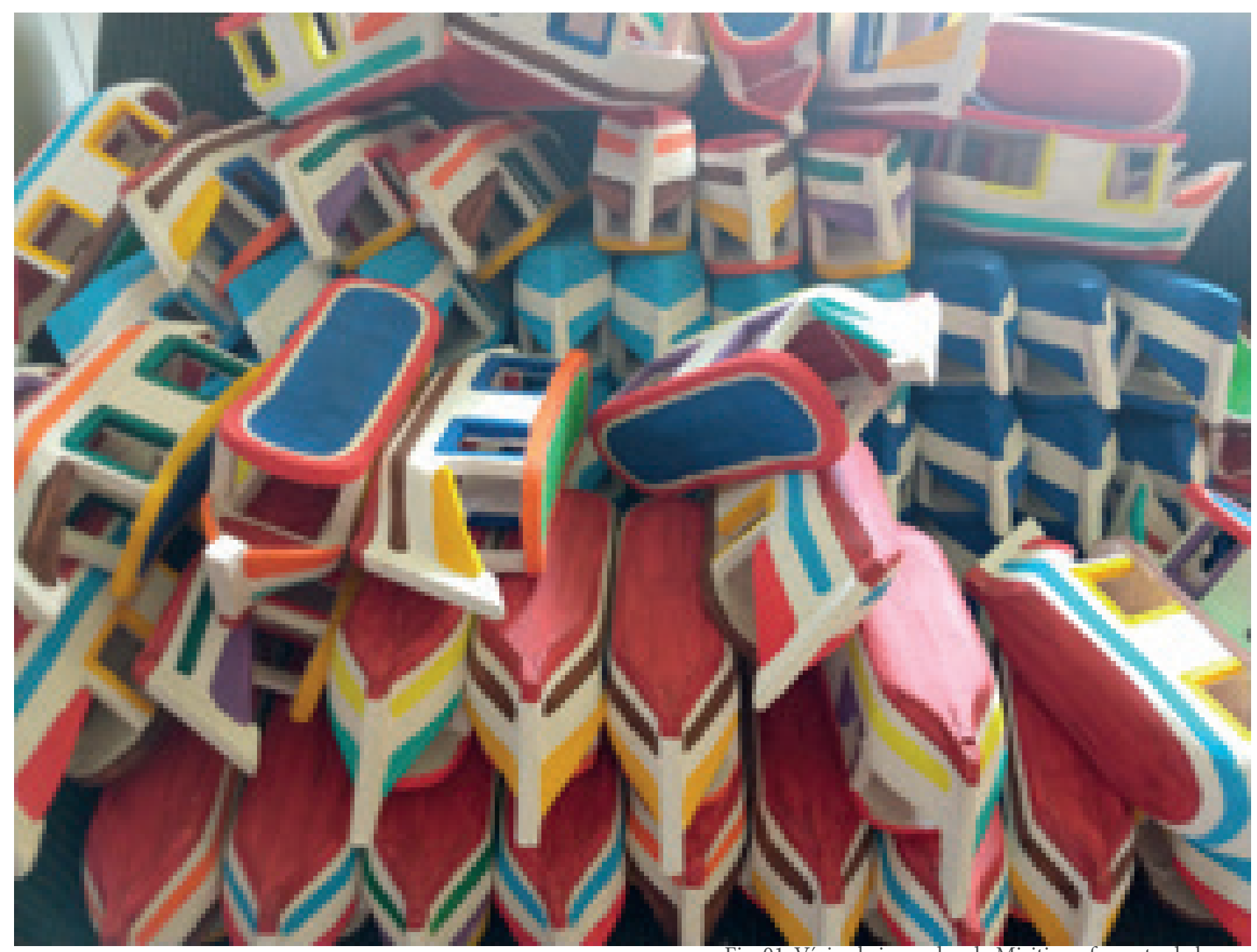

Fig. 01: Vários brinquedos de Miriti em formato de barco. Fonte: Foto Shirley Neves, 2018. 
Originários do município de Abaetetuba, cidade localizada a $56 \mathrm{~km}$ da capital Belém do Pará, é a mais de 200 (duzentos) anos conhecida por sua tradição em fabricar os brinquedos de miriti, que vêm de uma fibra leve da palmeira da área de várzea típica da região norte do Brasil. A confecção dos brinquedos se dá a partir da coleta dos talos da palmeira que são descascados, onde o artesão aproveita o miolo da árvore para representar todo seu imaginário popular, quase sempre em obras inéditas, cheia de cores e experiências vividas pela ludicidade amazônica. Santos (2016) também afirma que a construção do brinquedo de miriti estabelece uma íntima relação entre o artesãos e a arte, pois é através deste objeto, que eles demonstram suas intenções e gestos, reproduzindo cotidianos, inventando e reinventando saberes sociais e culturais de sua identidade amazônica.

O brinquedo de miriti, quando no processo de feitura, recebe de seu artesão a representação de seu cotidiano e memória, ele, inevitavelmente, evidencia uma relação com o mundo em que vive, sendo assim fácil encontrarmos brinquedos em alusão a barquinhos, pássaros, o boto, a cobraque-mexe, entre outros. A tradição do brinquedo de miriti por artesãos de Abaetetuba é um modo de fabricação que resgata a memória e os valores de um coletivo que precisa ser valorizada e mantida ano a ano. Em uma relação rotineira, o sujeito então vive numa busca constante pela ordem, pelo hábito cotidiano, ao mesmo tempo em que se lança em busca da aventura do mercado e de seu movimento. As culturas dos povos, sobretudo ribeirinho, as quais se consideram em vias de extinção estariam, em verdade, fortalecendo-se por meio de trocas cada vez mais intensas.

Em vista disto, este artigo versa para além da tradição e paixão pela obra, mas como ponto central pretende analisar a relação do brinquedo de miriti enquanto memória coletiva em contraponto com o consumo cultural durante a festa religiosa de Nossa Senhora de Nazaré em Belém de Pará. Propõe-se também discutir como o brinquedo de miriti compõe o cenário do consumo religioso, e sua relação com a tradição herdada de um povo.

Para a metodologia empregada, recorremos a Silva (2014, p. 145) que afirma que "pode ser definida como o conjunto de critérios e métodos utilizados para se construir um saber seguro e válido" daí que foram realizados dois métodos de análise. A pesquisa bibliográfica como método será constituída a partir de dados secundários propondo autores como: Maurice Halbwachs que trata da questão sobre memória coletiva e seus pontos de vista; de Éclea Bosi que enaltece a importância da lembrança que cria vínculos sociais. Além disto, terá contribuições acerca do conceito de cultura e brinquedo de miriti com Paes Loureiro e Ivamilton Santos, além de Silvio Figueiredo, entre outros.

\section{FUNDAMENTAÇÕES TEÓRICAS}

No ambiente amazônico, Paes Loureiro (2015) cita os brinquedos de miriti, onde, segundo ele, sua origem está perdida no tempo vago da oralidade dos amazônidas, ultrapassando uma realidade prática, no entanto, segundo ele, acredita-se que foram as crianças que começaram a fazer do miriti pequenos brinquedos, em virtude de o material ser leve e flutuar nas águas dos rios e igarapés, além de lugares que enchiam com a água da chuva, leveza esta metaforicamente chamada de isopor da Amazônia. Para o autor, "o brinquedo de miriti se resguarda protegido por sua cativante singeleza estética. $\mathrm{O}$ que atrai nele não é a complexidade de efeitos, mas o tempo de uma simplicidade atraente da infância nele concentrado" (LOUREIRO, 2015, p. 374).

Este fazedor das águas que compõe uma comunidade de significação que não dissocia a arte dos outros aspectos da vida social, bem como, a religiosidade, o trabalho, as relações familiares e a festa (GOMES, 2013). 
$\mathrm{Na}$ cidade, é fácil encontrar quem os fabrica. Isto porque o brinquedo de miriti não é somente um brinquedo qualquer, é, no dizer do autor:

Expressão dos sonhos dos ribeirinhos, das suas imagens comuns, de sua criatividade e sensibilidade em representar estes sonhos, contagiando pela espontaneidade das formas, num trabalho coletivo de muitas mãos, que se envolvem numa produção familiar. Este artesão é nutrido das experiências com a natureza e com o universo infantil do qual também é parte. (GOMES, 2013, p. 366).

Fig. 02: Atelier do Sr. Amadeu Gonçalves, em Abaetetuba. Fonte: Foto Shirley Neves, 2018.

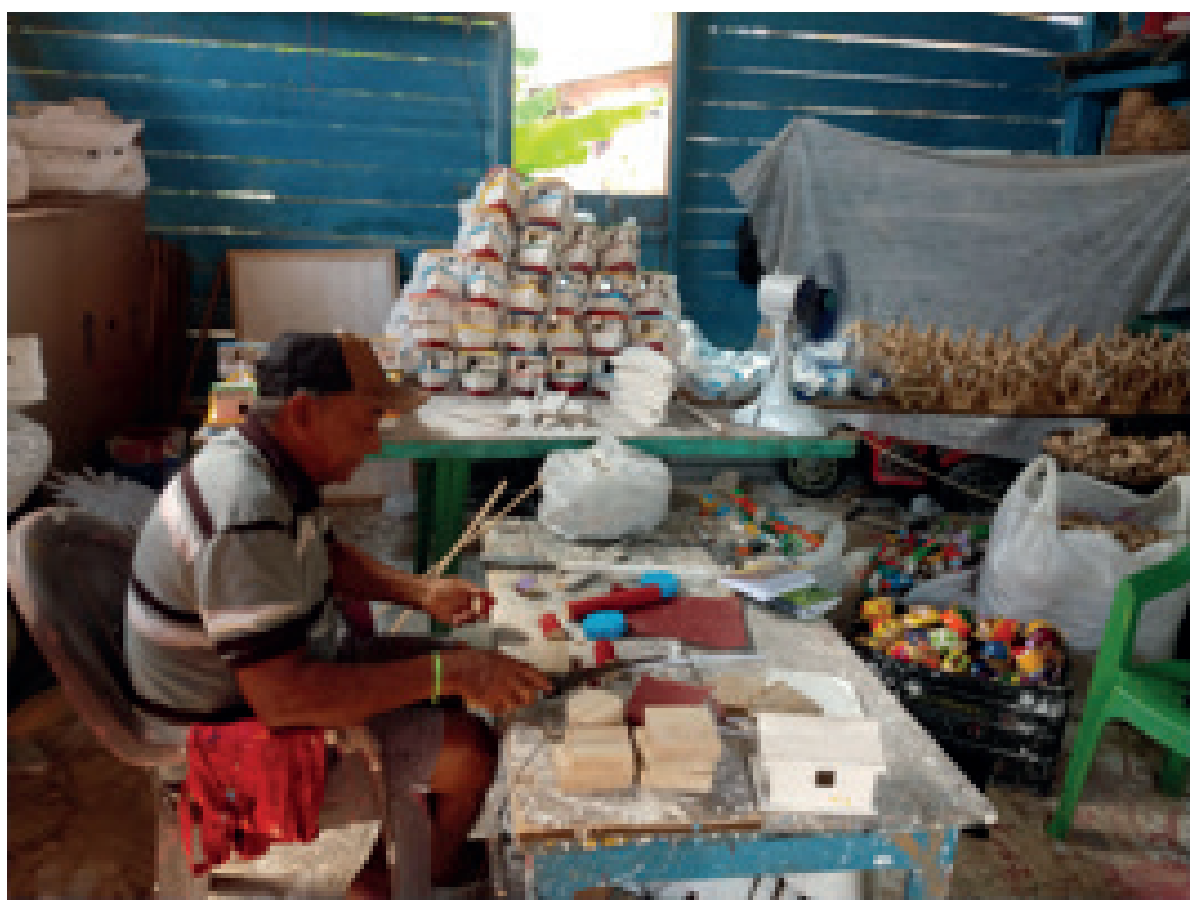

Loureiro (2015, p. 380) afirma que "nos brinquedos de miriti aparece uma espécie de outra natureza miniaturizada, gulliverzada, fruto do encontro entre a técnica e a intuição. Uma espécie de memória da natureza e da infância esculpida no efêmero da polpa de miriti”. Continuando, Gomes (2013, p. 224) assim enfatiza:

Uma vida ribeirinha, por definição, poderia ser encontrada nas artes de fazer, quando, por exemplo, o simbólico toma uma dimensão estética dominante num lugar qualquer e institui sentimentos, ideias, dando unidade à diversidade, dando forma ao disforme, conteúdo ao sem nome. A arte amarra o que estava desatado, dá forma ao informe, sentido ao caos, preenche vazios de sentido, definições as quais estão em consonância com o gênio poético de Shakespeare (1997). E, como a imaginação dá corpo a contornos de cópias ignotas, a pena do poeta lhes dá forma, e ao etéreo nada um lugar de morada e um nome.

Com os brinquedos de miriti nascem, assim, uma íntima relação entre o cotidiano de um povo e suas práticas culturais, enaltecidas por vezes, graças à condição aglutinadora de seus cruzamentos, entre o real e o simbólico. Ao longo do processo de produção de brinquedos de miriti, é possível perceber sua notoriedade, ainda mais quando do período dos festejos do Círio de Nazaré. Assim, é importante frisar que este brinquedo tem, em sua diversidade, um poder criativo e um saber-fazer com traços únicos que lhe engendram a categoria de um bem cultural. Com isso, entende-se que os saberes da tradição em fabricar os brinquedos de miriti, compreendidos como patrimônio cultural, acabam por ser alçados a um outro patamar de notoriedade, agora legitimado pelo discurso estatal e, também pelas ingerências de novas práticas discursivas 
na sociedade local, bem como pela mídia.

Para Hobsbawn (1984), a tradição é um conjunto de práticas reguladas e aceitas socialmente e que tem como objetivo inculcar significados (ideias, valores, condutas, atitudes, crenças) por meio da repetição, assim como acontece com a feitura do brinquedo de miriti.

No entanto, Matos (2010) chama atenção para o processo acelerado da globalização que passa a produzir novos sentidos simbólicos e interesses sobre os bens culturais, reordenando seu uso, como expõe:

\begin{abstract}
... devido ao processo de mundialização da cultura, muito de seu universo simbólico pode ser partilhado mundialmente por sujeitos dos mais diversos lugares, devido aos avanços técnicos contemporâneos, pela força que passam a ter as manifestações tradicionais populares dos lugares, como expressão da diversidade mundo e, também, pelo fato de que, gradativamente, os agentes organizadores da festa vêm dando "passos" para adequarem-na, ao processo de espetacularização das festas, às exigências organizacionais próprias de eventos que compõem o calendário de variadas empresas de turismo e a outras instâncias da sociedade de mercado que têm como alicerce a força política, ideológica e econômica do "mercado cultural" (MATOS, 2010, p. 140).
\end{abstract}

Atualmente, no entanto, percebemos que a evolução das mídias trouxe consigo uma nova forma na produção dos discursos e também na concepção do próprio valor da memória, que é capaz de nos envolver em uma teia de construções entre o mundo material e o social. Para tanto, Halbwachs (2006) afirma que para que a lembrança ocorra, é preciso ter vestígios sobre esse evento passado, sem que se tenha perdido o hábito e nem a qualidade de membro do grupo, para que seu testemunho tenha ideias comuns a seus membros. Isto ocorre em grande parte, pois segundo o autor, as memórias de um indivíduo jamais são só suas e ainda que nenhuma lembrança possa existir alheia da sociedade, esta seria como uma faculdade de armazenamento de informações, que o autor denomina como memória individual. Para ele, mesmo sendo particular, a lembrança sempre estará interagindo com a sociedade. "Diríamos que cada memória individual é um ponto de vista sobre a memória coletiva, que este ponto de vista muda segundo o lugar que ali ocupo e que esse mesmo lugar muda segundo as relações que mantenho com outros ambientes" (HALBWACHS, 2006, p. 69). O autor ainda enfatiza que,

para que a nossa memória se aproveite da memória dos outros, não
basta que estes nos apresentem seus testemunhos: também é preciso
que ela não tenha deixado de concordar com as memórias deles e
que existam muitos pontos de contato entre uma e outras para que a
lembrança que nos fazem recordar venha a ser constituída sobre uma
base comum. (HALBWACHS, 2006, p. 39).

Encontra-se no brinquedo de miriti justamente este tipo memória, em virtude da relação histórica com a festa, o que provoca em várias gerações uma espécie de mimese ${ }^{2}$, e também no fato dos artesãos, na sua grande maioria, herdarem o modo de fabricação do objeto, criando assim um significado para além de econômico-financeiro. A fabricação dos brinquedos de miriti perpassa ao longo dos anos por uma [re] significação não só em relação a sua cultura de consumo, mas também pela forte produção discursiva que passou a traduzir esta herança abaetetubense como símbolos, sobretudo da identidade para mercado. Trabalhar com a memória coletiva, é debruçar-se sobre o implícito que se estrutura sobre "um imaginário que o representa como memorizado" (ACHARD, 2007, p. 13).

No entanto, é preciso entender que a identidade cultural não pode ser esquecida, mesmo diante da avalanche do poder midiático. Segundo Vaz
2 Conceito significa imitação, recriação ou representação do mundo por meio de algum tipo de configuração.

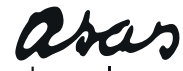

da palavra 
(2013, p. 172) "o regionalismo é apenas uma dentre tantas variantes do uso da língua no Brasil. Economistas, traficantes, médicos, surfistas, funkeiros e crentes brasileiros falam a mesma língua, mas usam linguagens diferentes". Vaz (2013) ainda afirma que há uma linguagem especial, que identifica as noções de pertença, enquanto sociedade e também de fronteira, enquanto demarcação de território cultural e, é preciso compreender que a identidade cultural não pode ser esquecida, mesmo diante da evolução das mídias. Para Halbwachs (2013), no entanto,

não basta reconstituir pedaço por pedaço a imagem de um aconteci-
mento passado para obter uma lembrança. É preciso que esta reconsti-
tuição funcione a partir de dados ou de noções comuns que estejam em
nosso espirito e também no dos outros, porque elas estão sempre pas-
sando destes para aqueles e vice-versa, o que será possível se somente
tiverem feito e continuarem fazendo parte de uma mesma sociedade, de
um mesmo grupo (HALBWACHS, 2013, $p$. 39).

O professor Fausto Neto (2007) ressalta que "a ênfase das operações de sentido da midiatização sobre a organização social e a expansão da autonomia do campo das mídias, estaria relacionada com fatores históricos, especialmente àqueles que geram o funcionamento da cultura no âmbito da sociedade contemporânea." (FAUSTO NETO, 2007, p. 93). Segundo García Canclini (2013, p. 289) "a mídia se transformou, até certo ponto, na grande mediadora e mediatizadora e, portanto, em substituta de outras interações coletivas".

\begin{abstract}
Os mercados de arte e artesanato, ainda que mantenham diferenças, coincidem em certo tratamento das obras. Tanto o artista que, ao pendurar os quadros, propõe uma ordem de leitura quanto o artesão, que articula suas peças seguindo uma matriz mítica, descobrem que o mercado os dispersa e ressemantiza ao vendê-los em países diferentes, a consumidores heterogêneos [...] ao artesão resta a possibilidade de repetir peças semelhantes, ou ir vê-las. (GARCÍA CANCLINI, 2013, p. 330).
\end{abstract}

Garcia Canclini (2013) esclarece que na verdade, o problema não é apenas conservar e resgatar essa memória coletiva, mas de inquirir, sobretudo, como estão se transformando, como estão interagindo com as forças da modernidade. Para Ortiz (2006), a globalização provoca um desenraizamento dos segmentos econômicos e culturais das sociedades nacionais, integrandoos a uma totalidade na distância dos grupos mais pobres, marginais ao mercado de trabalho e de consumo. Assim, nos últimos anos, sobretudo a partir dos anos 2000, tornou-se notório elucidar o famoso boom da cultura-mundo ${ }^{3}$ que acabou provocando novos usos e significados a práticas cotidianas e, principalmente, experiências culturais, a exemplo da fabricação do brinquedo de miriti em Abaetetuba.

Com isso, não se pode deixar de pensar que o brinquedo de miriti está sendo, cada vez mais acionado, em conexão com as demandas de mercado, em um verdadeiro paralelo diante de suas feituras artesanais historicamente construídas pela herança popular. Esse crescimento sob as práticas de consumo

3 Conceito abarcado pelos autores Gilles Lipovetsky e Jean Serroy na obra: A cultura - mundo: resposta a uma sociedade desorientada.

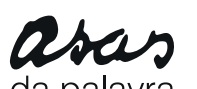

da palavra

VOL. 16 | N.1 | JUN. 2019 ISSN 1415-7950 em torno da cultura material começa, então, a demandar adaptações tanto no tipo, quanto no tema deste brinquedo. Este avanço do mercado em larga escala "propõe" ao artesão abaetetubense que ele passe a produzir brinquedos esteticamente mais vendáveis e com uma riqueza maior de detalhes, onde, então, passam a serem acionados como um objeto de mercado, posto durante o período da festa do Círio de Nazaré. 


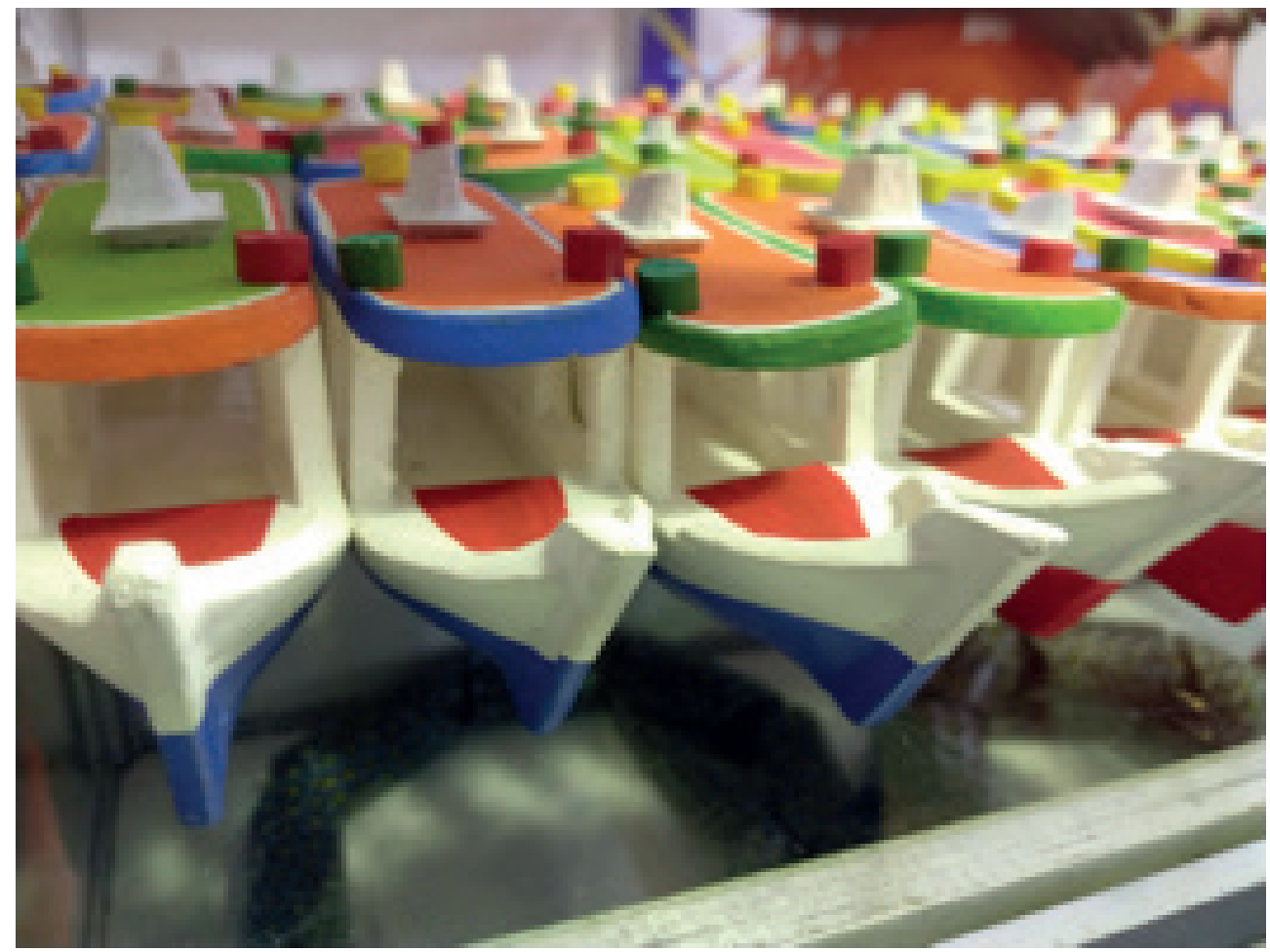

Fig. 03: Imagens de vários barcos de miriti sendo expostos em uma feira de artesanato durante os festejos do Círio, em Belém. Fonte: Foto Shirley Neves, 2018.

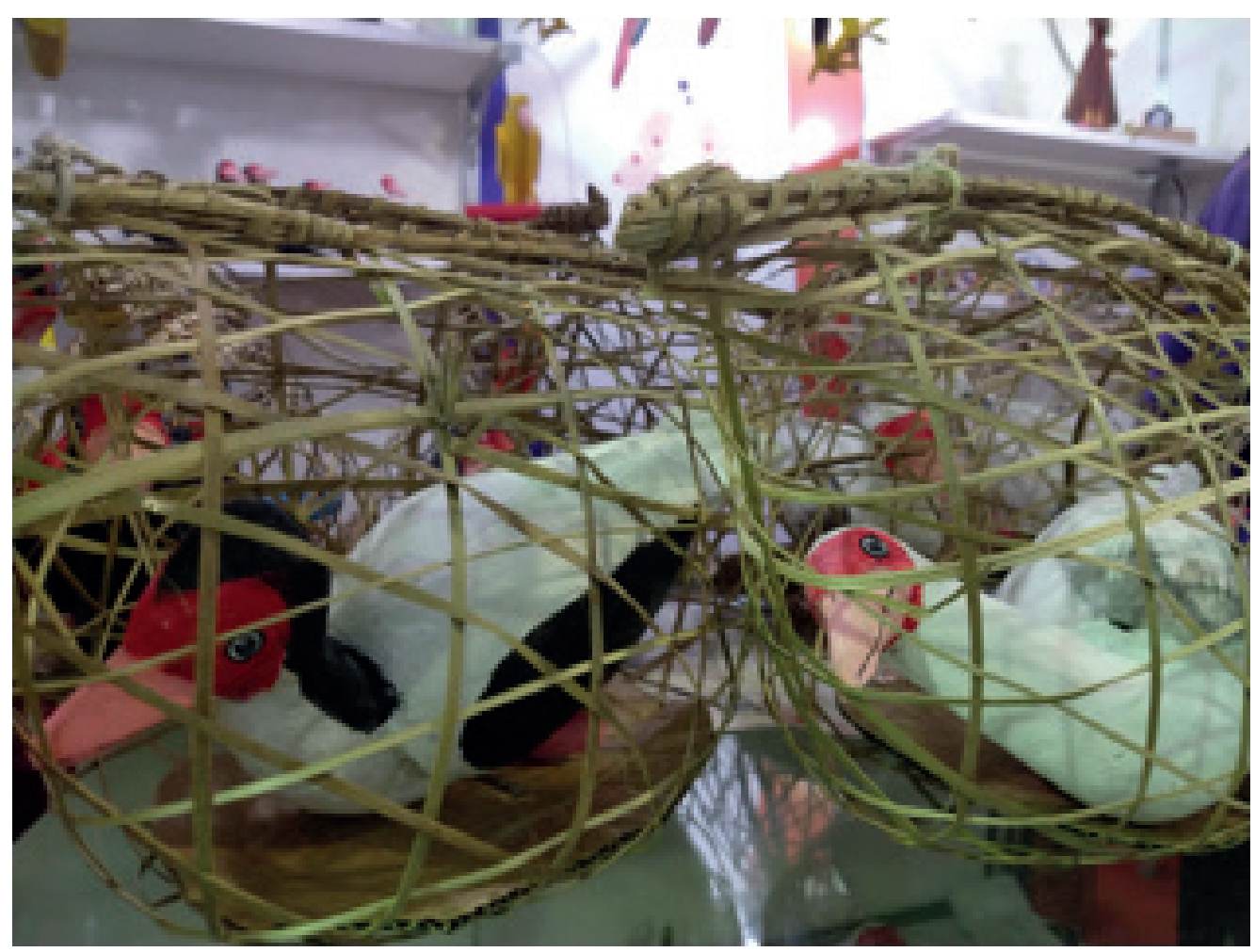

Fig. 04: Imagem da tradicional comida típica do Círio "pato no tucupi" feita de miriti.

Fonte: Foto Shirley Neves, 2018. 
Para Lipovetsky (2011, p. 32), “... é nessas condições que a época vê triunfar uma cultura globalizada ou globalista, uma cultura sem fronteiras cujo objetivo não é outro senão uma sociedade universal de consumidores". O brinquedo de miriti procura, assim, resistir ao tempo e a retórica de seu lugar, “... como o cartaz, a publicidade, a instalação, seu tempo é limitado à sua utilidade ou função" (LOUREIRO, 2015, p. 381). Estas mudanças culturais estão criando uma rápida mudança social, mas também, quase na mesma medida, sérios deslocamentos culturais. A vida cotidiana ribeirinha começa a ser revolucionada e suas transformações causam impactos inefáveis à estrutura simbólica.

Neste contexto, o brinquedo de miriti passa a ser pensado como um objeto que, ao longo do tempo, foi sendo reelaborado conforme a dinâmica própria de seus fazedores, mas que, conforme se observa nas últimas duas décadas, passou a ter seu nome cada vez mais associado a produtos, serviços e eventos que procuraram atrelar sua visibilidade ao brinquedo enquanto representação da cultura amazônica. Soma-se a isso, as transformações elencadas na própria estrutura da festa do Círio de Nazaré que possibilitou a elaboração de outros enunciados com relação ao brinquedo enquanto referente patrimonial, o que acabou por impactar nos modos de fazer e também nos usos do objeto não mais apenas como brinquedo, mas sobretudo, enquanto objeto referencial identitário, reelaborando sua condição e tornando-o ícone cultural, passando a ocupar bem mais as paredes de residências e pontos comerciais (notadamente aqueles voltados ao turismo) do que o chão e os rios nas brincadeiras infantis. Exemplo desta condição, temos na figura abaixo, onde o brinquedo transpõe o significado da comida típica da época dos festejos do Círio, em Belém.

Diante as transformações sob o impacto da globalização, alguns notórios autores do tema indicam que isso implica, também, no desprendimento da vida cotidiana da tradição, corroborando para a ideia de uma sociedade global. Giddens (2003), por exemplo, entende que as tradições são necessárias em uma sociedade para que se possa dar continuidade e formar a vida social, porém, ela deve ser defendida e perpetuada de uma maneira não tradicional para que, assim sejam possíveis suas trocas culturais. Mas, para o autor, o acesso a pessoas e conhecimentos diversos podem influenciar negativamente esses hábitos. Os padrões globais apresentados vêm sendo seguidos, deixando de lado os padrões locais e, dessa forma, promovendo uma descaracterização dos hábitos culturais em detrimento dos modelos globais aderidos. Desse modo, compreende-se que no caso em estudo, na medida em que o papel da tradição é afetado, novas dinâmicas são introduzidas na vida social, pois como afirma o autor:

Com frequência as tradições também sucumbem à modernidade, e
em algumas situações isso vem ocorrendo para o mundo todo. Tradi-
ção que é esvaziada de seu conteúdo, e comercializada, torna-se kits-
ch - as bugigangas que se compram na loja do aeroporto. Tal como
desenvolvida pela indústria da herança, herança é tradição reemba-
lada como espetáculo. Os prédios restaurados nos locais turísticos,
podem parecer esplêndidos, e a restauração pode parecer autêntica
até os minimos detalhes. Mas a herança que é assim protegida está
dissociada da seiva da tradição que é sua conexão com a experiência
que é a vida cotidiana (GIDDENS, 2003, p. 54).

Assim, entende-se que há uma tensão entre o local e o global que pode ser traduzida, entre outras maneiras, pela forma como agem os agentes econômicos sobre o mercado de bens e serviços que passam a serem notabilizados como representações de lugares, objetos religiosos, comidas típicas etc. São mudanças nos nossos costumes atreladas ao fenômeno da globalização que mundializam nossos costumes. Sobre isto, Santos (2010, p. 143-144) pondera:

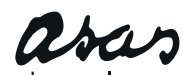

da palavra 
Sem dúvida, o mercado vai impondo, com maior ou menor força, aqui e ali, elementos mais ou menos maciços da cultura de massa, indispensável, como ela é ao reino do mercado, e a expansão paralela das formas de globalização econômica, financeira técnica e cultural. Essa conquista, mais ou menos eficaz segundo os lugares e as sociedades, jamais é completa, pois encontra a resistência da cultura preexistente. Constituem-se, assim formas mistas sincréticas, entre as quais, oferecida como espetáculo, uma cultura popular domesticada associando a um fundo genuíno de formas exóticas que incluem novas técnicas.

Nessa nova realidade, que graças ao advento dos novos aparatos tecnológicos e informacionais que possibilitam a instantaneidade das ações e acontecimentos que invadem e criam novos territórios, acontecem novas práticas de consumo em torno da cultura material, demandadas pelas estratégias de mercado. Segundo Santos (2010), a mídia passa, então, a estar presente no cotidiano das pessoas de todas as classes sociais e é a grande responsável por transmitir essa cultura mais globalizada e, assim, sugere um padrão de vida e de consumo que devem ser seguidos para alcançar a felicidade.

No caso dos brinquedos de miriti, observa-se que eles também passaram a atender essas estratégias, na medida em que sua produção foi sendo gradativamente alterada em função de um alinhamento cada vez maior à grande festa da padroeira dos paraenses, fato este, impulsionado por diferentes meios de comunicação que passaram a ser um dos principais agentes de promoção e divulgação da arte ribeirinha enquanto elemento estético representativo do Círio de Nazaré. Desta forma, Sodré (2010, p. 165) esclarece que "... na fronteira do individual com o social, tais representações incorporam conteúdos [...] relativos à vida cotidiana, reorganizando-os numa modalidade de saber adaptada à fácil comunicação e sobre uma maneira de interpretação que produza sentidos e crie referências simbólicas da relação do brinquedo com a festa".

\section{CONCLUSÃO}

Portanto, deixamos como reflexão neste estudo, que a lógica que fica implícita no trânsito de atores e símbolos culturais estabelecido na relação entre a cidade de Abaetetuba e a capital Belém podem nos ajudar a compreender não apenas os vínculos que a prática do artesanato mantém com uma memória afetiva ligada à cultura ribeirinha, mas, sobretudo, os aspectos que o fizeram se tornar símbolo de consumo cultural. Os brinquedos de miriti se ligam às experiências devocionais envolvidas em sua vinculação com a feira do Círio de Nazaré, mas que, em alguns momentos, provêm das lógicas de troca comerciais. O contexto devocional da fé em Nossa Senhora de Nazaré é conjugado com as aflições advindas da sua condição ribeirinha, principalmente, sua memória coletiva, que com o tempo estão transformando-o em produto de consumo.

\section{REFERÊNCIAS}

ACHARD, P. et al. Papel da memória. Tradução e introdução: José Horta Nunes. $2^{\mathrm{a}}$ ed. Campinas, São Paulo: Pontes, 2007.

BONNA, Mízar. Dois séculos de fé. Belém: CEJUP, 1993.

BOSI, Éclea. O tempo vivido da memória: ensaios da psicologia social. São Paulo: Ateliê, 2003.

FAUSTO NETO, Antônio. Fragmentos de uma «analítica» da midiatização. In: Revista Matrizes, Vol 1 No 2, Universidade de São Paulo, 2008. 
REVISTA DO PROGRAMA DE PÓS-GRADUAÇÃO EM COMUNICAÇÃO, LINGUAGENS E CULTURA DA UNIVERSIDADE DA AMAZÔNIA

FIGUEIREDO, Silvio Lima (org). Círio de Nazaré, festa e paixão. Belém: EDUFPA, 2005.

GARCÍA CANCLINI, Nestor. Culturas Híbridas. $3^{\mathrm{a}}$ ed. São Paulo, EDUSP, 2013.

GIDDENS, Anthony. Consequências da modernidade. São Paulo: Unesp, 2003.

GOMES, Jones da Silva. Cidade da Arte: uma poética da resistência nas margens de Abaetetuba. Tese da Universidade Federal do Pará, Instituto de Filosofia e Ciências Humanas, Programa de Pós-Graduação em Ciências Sociais. Belém, 2013.

HALBWACHS, Maurice. A memória coletiva. Trad. de Beatriz Sidou. São Paulo: Centauro, 2006.

LOUREIRO, João de Jesus Paes. Cultura Amazônica: uma poética do imaginário. $4^{\mathrm{a}}$ ed. Belém, PA: Cultura Brasil , 2015.

LIPOVESKTY, Gilles. A cultura-mundo: resposta a uma sociedade desorientada. São Paulo: Companhia das Letras, 2011.

MORAIS, Luiz Carlos. Aprendendo com o brinquedo na arte com o miriti: um estudo do brinquedo popular, através de seus elementos fundamentais aplicados na educação. Belém: SECULT/FCPTN, 1989.

ORTIZ, Renato. Cultura brasileira e Identidade nacional. São Paulo: Brasiliense, 2006.

SANTOS, Ivamilton Nonato Lobato dos. BRINQUEDO DE MIRITI patrimônio histórico cultural perspectiva matemática. Belém, PA. Cromos: 2016

SILVA, José Maria. Apresentação de trabalhos acadêmicos: normas e técnicas. $8^{\mathrm{a}}$ ed. Petrópolis, RJ: Vozes, 2014.

\section{NOTA}

* Este trabalho é um recorte do artigo elaborado para apresentação do XV enecult- Encontro de Estudos Multidisciplinares em Cultura, a ser realizado em agosto de 2019, na cidade de Salvador- BA.

Recebido em 01 Jun 2019 ｜Ａprovado em 18 Jun 2019

Shirley do Socorro Moura das NEVES

Mestre em Comunicação pelo programa de Pós-Graduação em Comunicação, Linguagens e Cultura da Universidade da Amazônia. Professora do curso de Comunicação Social da Faculdade Estácio do Pará. shirleysfmoura@gmail.com

Edgar Monteiro CHAGAS JUNIOR

Doutor pelo Programa de Pós-Graduação em Sociologia e Antropologia da Universidade Federal do Pará. Coordenador do Programa de Pós-Graduação em Comunicação, Linguagem e Cultura da Universidade da Amazônia. edgarchagas@yahoo.com.br 